\title{
Mitochondria of human Leydig cells as seen by high resolution scanning electron microscopy*
}

\author{
Alessandro Riva ${ }^{1}$, Bernard Tandler ${ }^{2}$, Tatsuo Ushiki ${ }^{3}$, Paolo Usai ${ }^{4}$, Raffaella Isola ${ }^{1}$, \\ Gabriele Conti ${ }^{1}$, Francesco Loy ${ }^{1}$, and Charles L. Hoppel ${ }^{5}$ \\ ${ }^{1}$ Department of Cytomorphology, School of Medicine, University of Cagliari, Cagliari, Italy; ${ }^{2}$ Department of \\ Biological Sciences, School of Dental Medicine, Case Western Reserve University, Cleveland, Ohio, USA; \\ ${ }^{3}$ Division of Microscopic Anatomy and Bio-imaging, Niigata University Graduate School of Medical and \\ Dental Science Niigata, Japan; ${ }^{4}$ Urology Clinic, University of Cagliari, Cagliari, Italy; and ${ }^{5}$ Department \\ of Pharmacology, School of Medicine, Case Western Reserve University, Cleveland, Ohio, USA
}

Summary. The three-dimensional ultrastructure of over 1000 mitochondria in human Leydig cells (from twelve sexually mature patients) was examined by high resolution scanning electron microscopy (HRSEM) of osmiummacerated specimens, as well as by transmission electron microscopy of conventional ultrathin sections. The stereopair imaging of the osmium-macerated specimens by HRSEM is also very useful for investigating the threedimensional structure of cytoplasmic membranous organelles with great clarity. The mitochondria, which mainly are elongated (although some are ovate), possess cristae that are almost exclusively tubular and that occasionally display constrictions and terminal bulbules. Lamelliform cristae are quite rare. Occasionally, the tubular cristae are joined together to form a simple network. Classic crista junctions could not be identified with certainty, although the base of the tubular cristae might correspond functionally to such junctions.

Received September 4, 2009

* This work was supported in part by NIH grant PO1 AG15885 and a grant from the Fondazione Banco di Sardegna.

Address for correspondence: Prof. Alessandro Riva, MD, Department of Cytomorphology, Cittadella Universitaria, Monserrato, Cagliari, I-09042 Italy

Tel: + 39-070-675-4027, Fax: + 39-070-675-4003

E-mail: riva@unica.it
As a whole, in line with the identical and common embryological origin of adrenal cortex and gonads, mitochondria of human Leydig cell closely resemble those of steroidogenic cells of human suprarenal cortex treated by the same maceration method.

\section{Introduction}

Leydig cells (interstitial cells) are endocrine cells lying between the testicular seminiferous tubules and are the sites of synthesis of the main male hormone, testosterone (Ewing and Zirkin, 1983), as well as other androgens. Cytologically, they are similar to other steroid-producing cells - they are characterized by an extensive smooth endoplasmic reticulum and an abundance of mitochondria (Zirkin et al., 1980; Ewing and Zirkin, 1983; Mori, 1984). In earlier studies (Bhalla et al., 1987; Kerr, 1991) on Leydig cells of the rat and human examined by conventional transmission electron microscopy (TEM), mitochondria are described as possessing vesicular or tubulovesicular cristae like those of other steroidsecreting organs such as the suprarenal cortex (Fawcett, 1981). In contrast, on the basis of findings obtained by TEM of ultrathin sections, Prince (1999) reported that human Leydig cell mitochondria also contained a mixture of both lamelliform and tubular cristae. However, following the introduction of electron tomography of thicker sections, data obtained by conventional TEM of ultrathin sections have been subjected to criticism. On the basis of their pioneering work using electron tomography, Mannella et al. (1994) reported that, at variance with 

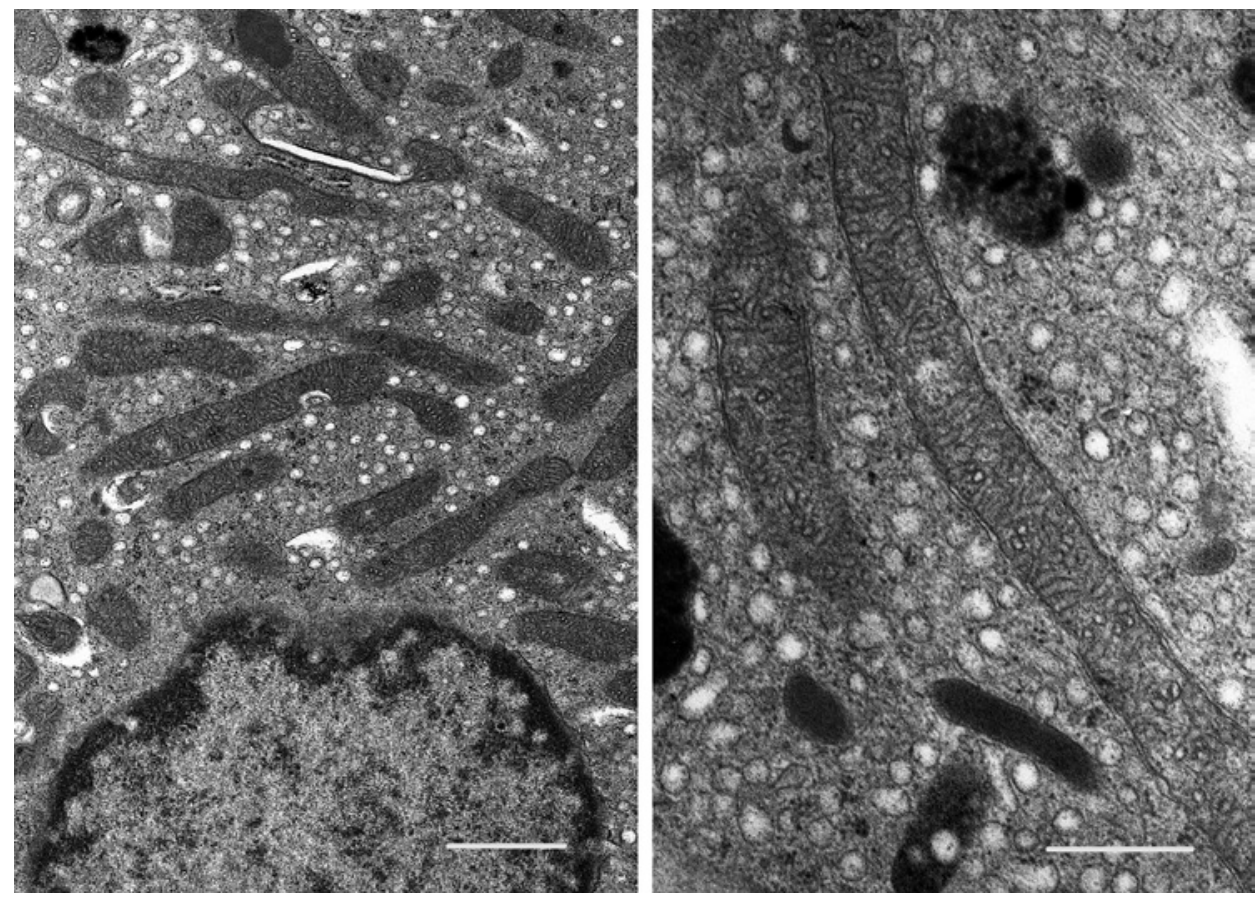

Fig. 1. Micrographs of human Leydig cells by convensional transmission electron microscopy (TEM). a: Many mitochoncria are found in the Leydig cell. b: At higher magnification, each mitochondrion is seen to contain numerous cristae, which appear either lamelliform or tubular in thin section. Bar: $1 \mu \mathrm{m}$ (a), 600nm (b)

the then prevailing view that mitochondria had mostly lamelliform cristae, the vast majority of these organelles had tubular cristae. The same authors also stated that this had been first demonstrated by osmium maceration studies carried out by high resolution scanning electron microscopy (HRSEM) (Lea and Hollemberg, 1989). The sole criticism that Mannella et al. (1994) had of HRSEM results is that in order to investigate their internal structure by the latter method, mitochondria must be cleaved, so that only a portion of the organelle is exposed. Moreover, in a later review that dealt with application of electron tomography to mitochondrial research, Mannella (2001) pointed out that "Electron Tomography is ill suited to address questions that requires statistical answers", since it involves the 3-D reconstruction of a very limited number of selected specimens.

For these reasons, we were not persuaded that the descriptions on the morphology of Leydig cell mitochondrial cristae obtained either by conventional TEM (reported by Prince, 1999, 2002) or by electron tomography (Prince and Buttle, 2004), the latter study employing just four mitochondria from a single specimen, were not necessarily accurate. This led us to employ the osmium maceration method to investigate the cristal configuration of mitochondria of human Leydig cell, in order to ascertain their 3-D configuration in a large mitochondrial population. Results are compared with the appearance of mitochondrial cristae in human suprarenal gland subjected to the same methodology (Riva et al. 2003).

\section{Material and Methods}

Testicular specimens were derived from 12 patients by surgical biopsy. Informed consent was obtained before surgery from each patient and approval was granted by the local ethics committee (ASL8, Cagliari). The patients ranged in age from 19 to 67 years and none showed signs of hypogonadism. Moreover, serum values of both testosterone and prolactin were in the normal range. Tissues were prepared for HRSEM by methods detailed in 
Fig. 2. Survey HRSEM micrographs of the cytoplasm of human Leydig cells. In a most mitochondria were not transected, so they show their 3-D shape in its entirety; note two branching mitochondria (arrows). In b all of the mitochondria exhibit tubular cristae. These organelles are buried in a welter of SER membranes. Bars: $1 \mu \mathrm{m}$
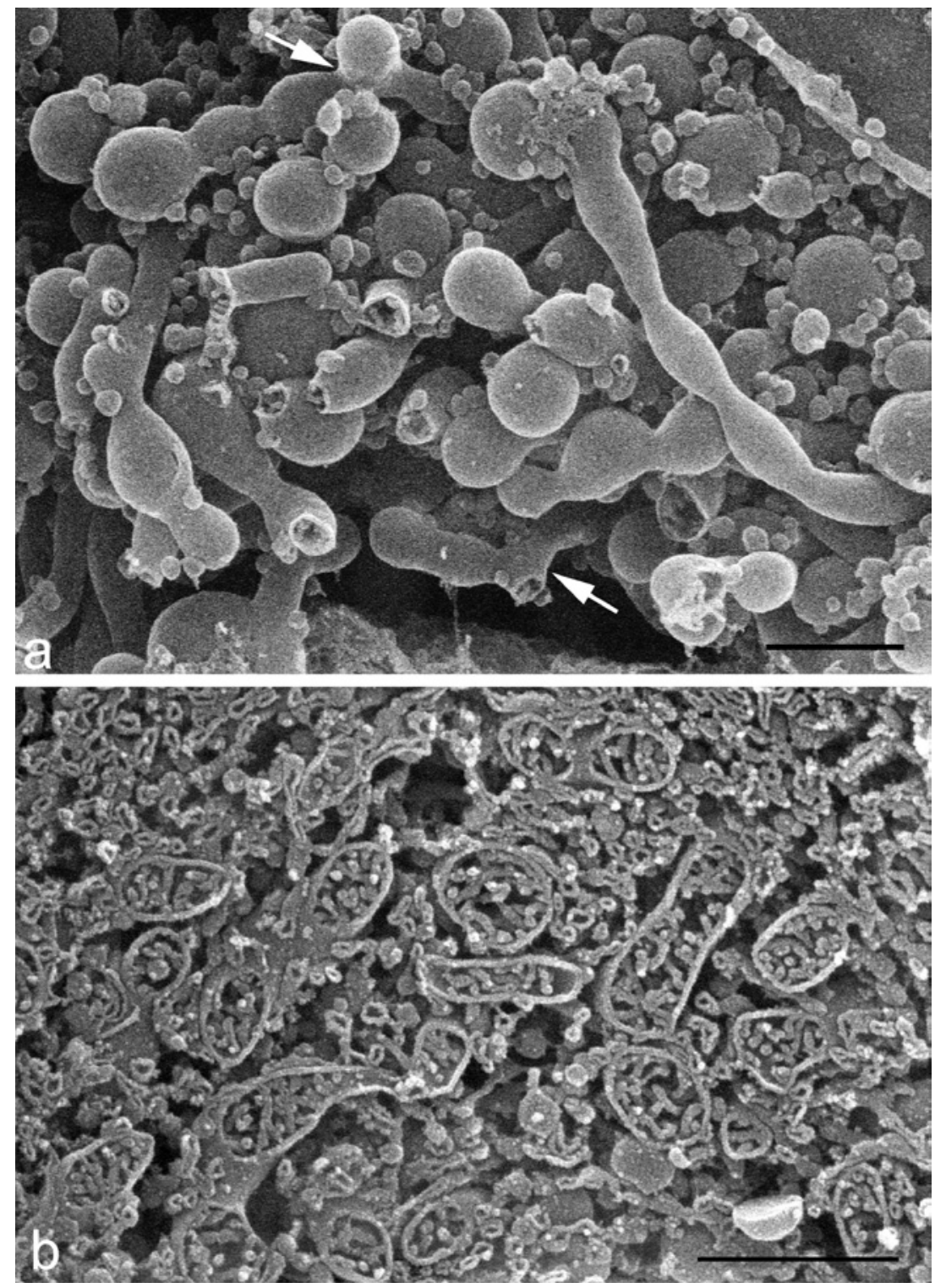

Fig. 3. Percentage of mitochondria with lamellar cristae $(3.5 \%)$ versus those with tubular cristae $(96.5 \%) . \mathrm{N}=1000$.

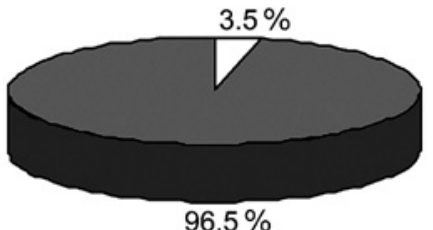



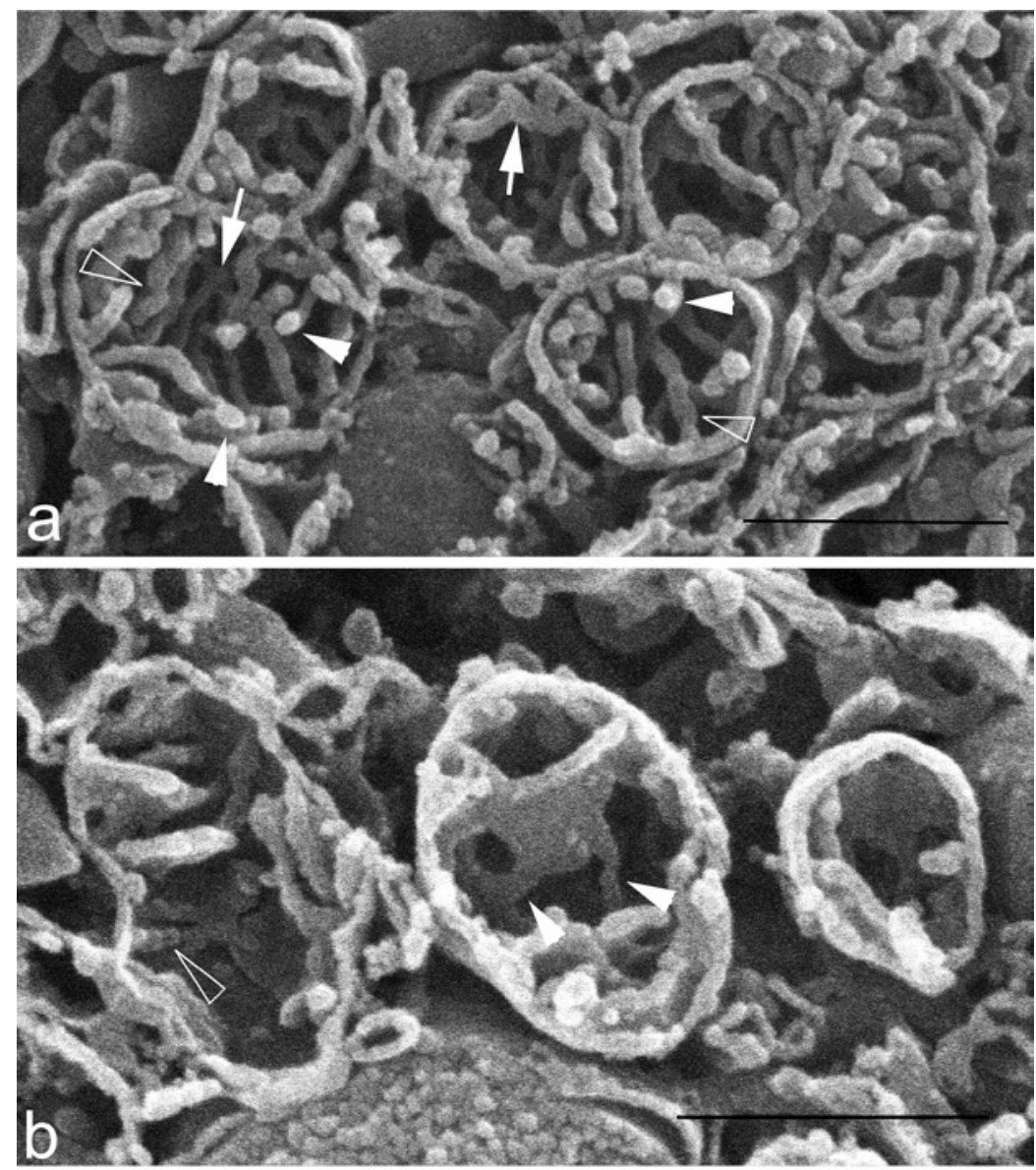

Fig. 4. a: Leydig cell mitochondria with tubular cristae, some of which show faint constrictions (open arrowheads) and terminate in a bulbule (arrowheads); some mitochondria cristae are branched (arrows); b: Mitochondria with tranverse cristae that are connected to tubular ones (arrowheads); also note tubular cristae with constrictions (open arrowheads); c: Mitochondrion
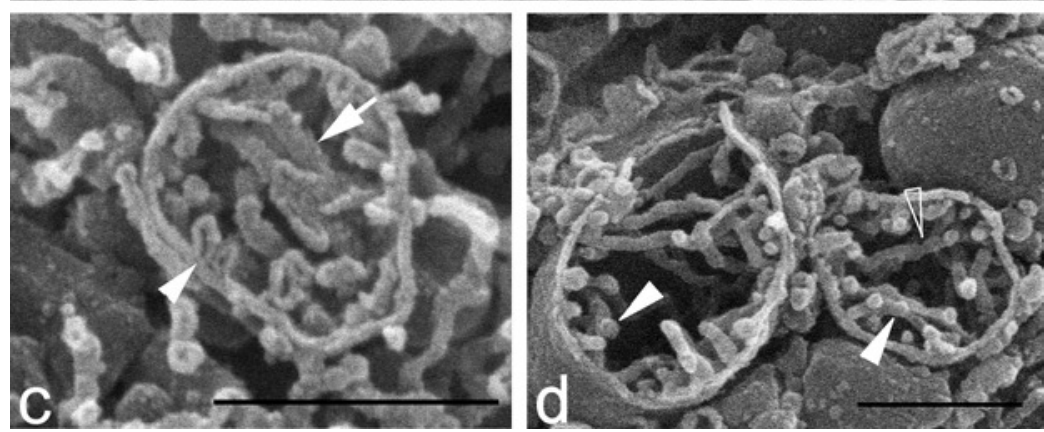
with ribbon-like cristae (arrow); the arrowhead indicates a point where a crista is attached to the boundary membrane; the slight narrowing of the neck of this crista may be indicative of a crista junction. d: Mitochondria exhibiting tubular cristae with constrictions (open arrowhead) and bulbules (arrowheads). Bars: $600 \mathrm{~nm}$

earlier articles (Riva et al., 1999, 2003, 2007), which are summarized as follows:

1. Fixation of tissue strips $(1-2 \mathrm{~mm} \times 7 \mathrm{~mm})$ with $0.5 \%$ glutaraldehyde $+0.5 \%$ paraformaldehyde in 0.1 $\mathrm{M}$ cacodylate buffer ( $\mathrm{pH} 7.2)$ for $15 \mathrm{~min}$ at room temperature (RT).

2. Rinsing in PBS $(3 \times 10 \mathrm{~min})$ at RT

3. Postfixation with $1 \% \mathrm{OsO}_{4}-1.25 \% \mathrm{~K}_{4} \mathrm{Fe}(\mathrm{CN})_{6}$ in distilled $\mathrm{H}_{2} \mathrm{O}, 2 \mathrm{~h}$ in the dark at $4{ }^{\circ} \mathrm{C}$

\section{Rinsing in PBS $(3 \times 10 \mathrm{~min})$ at $\mathrm{RT}$}

5. Sectioning: specimens were embedded in $1 \%$ agarose in distilled $\mathrm{H}_{2} \mathrm{O}$ and cut into $150 \mu \mathrm{m}$ thick sections by a TC2 Sorvall tissue sectioner.

(5a. As an alternative to sectioning indicated above, some specimens were rapidly frozen in liquid nitrogen, and then shattered by a blow of a hammer. The multiple salvaged fragments were treated in the same manner as were tissue slices). 
Fig. 5. Stereo-pair images of human Leydig cell mitochondria by HRSEM. These two micrographs are displayed as an anaglyph, which can be observed stereoscopically by using red-blue glasses. Bar: $600 \mathrm{~nm}$
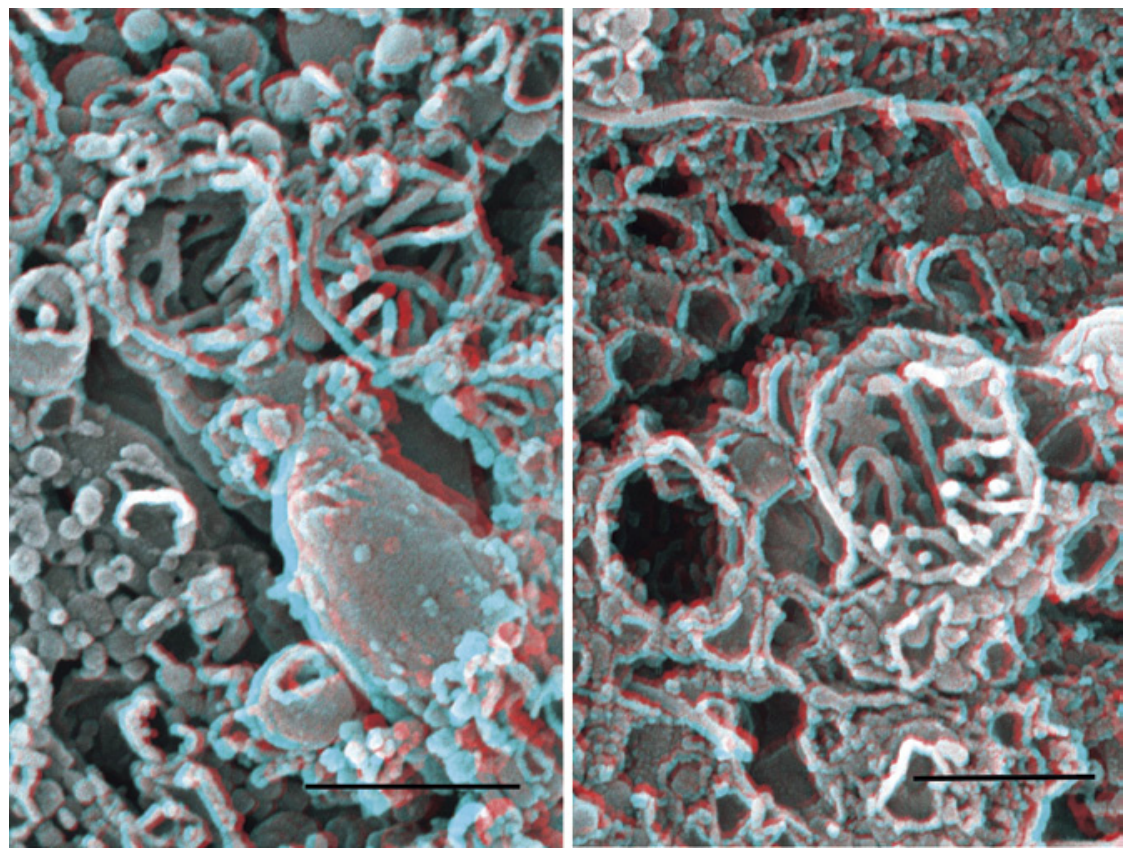

6. Rinsing in PBS $(3 \times 10 \mathrm{~min})$ at $\mathrm{RT}$

7. Second postfixation with $1 \% \mathrm{OsO}_{4}-1.25 \% \mathrm{~K}_{4} \mathrm{Fe}(\mathrm{CN})_{6}$ in distilled $\mathrm{H}_{2} \mathrm{O}$ for $1 \mathrm{~h}$ in the dark at $4{ }^{\circ} \mathrm{C}$

8. Rinsing in PBS $(3 \times 10 \mathrm{~min})$ at $\mathrm{RT}$

9. Maceration with $0.1 \% \mathrm{OsO}_{4}$ in $\mathrm{PBS}$ for $44-48 \mathrm{~h}$ at $25^{\circ} \mathrm{C}$

10. Rinsing in PBS $(3 \times 10 \mathrm{~min})$ at RT

11. Dehydration through acetone of ascending concentrations, followed by critical point drying with $\mathrm{CO}_{2}$, and coating with platinum $(2 \mathrm{~nm})$ by a sputter coater (Emitech 575 turbo sputtering apparatus)

These samples were observed in an HRSEM (Hitachi S4000 field emission SEM, Hitachi Hitechnologies, Tokyo) at 15-20 kV. Stereo-pair images also were obtained by tilting samples at $8^{\circ}$ and displayed as anaglyphs.

Some specimens fixed with the aldehyde fixative mentioned above were embedded in epoxy resin according to conventional methods for TEM and processed for light microscopy and TEM.

\section{Results}

Based on both light microscopy of semithin sections and conventional TEM of ultrathin sections, Leydig cells in the specimens observed in this study showed no signs of pathology. By TEM, it was difficult to visualize the entire shape of mitochondria, but many elongated mitochondria were seen (Fig.1a); these organelles contain well-developed cristae, which appear either lamelliform or tubular in such thin sections (Fig. 1b). In contrast, HRSEM of osmium-extracted specimens clearly revealed that entire mitochondria were mostly elongated with recurrent constrictions, often being surrounded by elements of smooth endoplasmic reticulum (Fig. 2a).

Despite careful and extensive examination by HRSEM of our samples (more than 1000 individual mitochondria inspected), relatively few mitochondria displayed lamelliform cristae that conformed to the description based on high voltage TEM (Prince and Buttle, 2004); in other words, only $3.5 \%$ were lamelliform (Fig. 3). Most of the cristae were tubular (Fig. 4a,d) and terminated in bulbules; some exhibited faint periodic constrictions (Fig. 4a, b, d ). In a very few instances, tubular cristae expanded to form a lamellar continuation (Fig. 4a, b). Sometimes cristae were branched or they assumed a flattened tubular (ribbon-like) shape (Fig. 4c). The stereopair images by HRSEM also clearly showed that tubular cristae are predominant in the mitochondria of the human Leydig cells (Fig. 5). A schematic drawing of a typical mitochondrion in section is shown in Figure 6.

Because the few lamelliform extensions were not in direct apposition to the boundary membrane, classic crista junctions (Perkins et al., 1997) were not discernible 
in Leydig cell mitochondria. We observed what could be construed as crista junctions in only a few cases, mainly as tubular bifurcations anchored to the boundary membrane (Fig. 4c, arrowhead). The tubular cristae, which seldom spanned the inner compartment, often ended in a bulbous termination (Fig. 4a, d and Fig. 5a, b). Some tubular cristae joined others to form a simple network (Fig. 4a). We did not encounter a single example of the lamellar associations described by Prince and Buttle (2004).

\section{Discussion}

The present study involved over 1000 mitochondria in human Leydig cells as observed by HRSEM of osmium macerated tissues. In our previous HRSEM study of osmium-macerated human adrenocortical mitochondria (Riva et al., 2003), we reported that most of these organelles had tubular cristae that exhibited evident periodic constrictions and that had a bulbous tip. In the present study, we found that most human Leydig cell mitochondria, regardless of overall organelle shape, also had tubular cristae that often had bulbous tips, except that these terminations were less prominent than those in the adrenocortical mitochondria and that the constrictions were less obvious and less frequent. Besides these slight differences, some cristae were in the form of ribbons and simple networks.

We also previously suggested that, in the adrenal gland, these crista constrictions might act to subcompartmentalize individual cristae (Riva et al., 2003). In this regard, crista junctions have been suggested to act as sentinels for the entrance and departure of molecules into and from cristae (Frey and Manella, 2000). It is now obvious that virtually all steroid-secreting cells have mitochondria with tubular cristae (Fawcett, 1981). Steroidogenesis depends on the organelles being "energized, polarized, and actively respiring" (Hales et al., 2005), a metabolic state that profoundly influences crista morphology.

In contrast to the report by Prince and Buttle (2004) who found that human Leydig cells mitochondrial cristae are prevalently lamelliform, we ascertained that the vast majority of cristae in these organelles are tubular. It should be emphasized that our study encompassed more that 1000 mitochondria derived from biopsies of 12 patients, as compared with Prince and Buttle's (2004) reconstructions of just four organelles, which were derived from only one patient; thus our findings bid fair to be more representative of the true structure of human Leydig cell mitochondria.

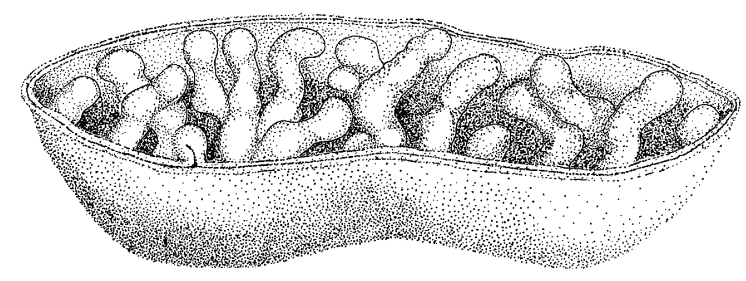

Fig. 6. Schematic drawing illustrating the internum of a mitochondrion of a human Leydig cell.

Another feature of human Leydig cell mitochondria that Prince (2002) and Prince and Buttle (2004) call attention to is 'lamellar associations', aggregates of closely-apposed lamelliform cristae. Such cristae are joined to the boundary membrane by crista junctions and are said to be interconnected. These authors claim that such lamellar associations are unique to steroidproducing mitochondria. It is true that such aggregates have been observed in glioblastoma multiforme cells (Tani et al., 1971), and hepatocytes (Riede and Nobmann, 1974; Valdivia and Berger, 1976; Walter et al., 1980); mitochondria in both glial and hepatic cells are able to import cholesterol, which can be metabolized via cytochrome P450 to form steroids. However, similar aggregations of mitochondrial cristae have been reported to occur in a variety of non-steroidal cells including thyroid follicular cells (Nathaniel, 1976), duct cells in salivary glands (Tandler, 1986; Toyoshima and Tandler, 1986), and tumour cells of the latter organs (Tandler and Erlandson, 1983). In the parotid seromucous endpiece cells of the omnivorous bat, Carollia perspicillata, the aggregated cristae are connected to their nearest neighbours by short, presumably proteinaceous, bridges (Tandler et al., 1988). The functional significance of such cristal aggregates is unknown-all that can be said at this time is that they are not unique to steroid-secreting cells. In recent reviews on the structure and dynamics of mitochondria, based mostly on electron tomography, Mannella $(2006,2008)$ states that the shape of inner membrane influences mitochondrial function and that its changes might reflect a novel regulatory mechanism. Thus the lamelliform cristae and the lamellar associations reported by aforementioned authors may simply represent transient functional states.

In summary, this study provides new information concerning the ultrastructure of human Leydig cell mitochondria that has implications for the function of these organelles. Furthermore, it illustrates the utility of 
HRSEM combined with osmium-extraction of tissues in establishing with comparative ease the three-dimensional configuration of cellular structures in general and of mitochondria in particular.

\section{Acknowledgments}

We appreciate the help of Steve Ingalls and Dr. Hisashi Fujioka in preparing the figures.

\section{References}

Bhalla VK, Rajan VP, Burgett AC, Sohal GS: Interstitial cell heterogeneity in rat testes. I. Purification of collagenase-dispersed Leydig cells by unit gravity sedimentation and demonstration of binding sites for gonadotropin in light cells versus enhanced steroidogenesis in heavier cells. J Biol Chem 262: 5313-5321 (1987).

Ewing LL, Zirkin B: Leydig cell structure and steroidogenic function. Recent Prog Horm Res 39: 599635 (1983).

Fawcett D: The cell. WB Saunders Company, Philadelphia, 1981(p. 448-461).

Frey TG, Manella CA: The internal structure of mitochondria. Trends Biochem Sci 25: 319-324 (2000).

Hales DB, Allen JA, Shankara T, Buck S, Diemer T, Hales KH: Mitochondrial function in Leydig cell steroidogenesis. Ann NY Acad Sci 1061: 120-134 (2005).

Kerr JB: Ultrastructure of the seminiferous epithelium and intertubular tissue of the human testis. J Electron Microsc Tech 19: 215-240 (1991).

Lea PJ, Hollenberg MJ: Mitochondrial structure revealed by high resolution electron microscopy. Am J Anat 184: 245-257 (1989).

Mannella CA: Application of electron tomography to mitochondrial research. Methods Cell Biol 65: 245-256 (2001).

Mannella CA: Structure and dynamics of the mitochondrial inner membrane cristae. Biochim Biophys Acta 1763: 542-548 (2006).

Mannella CA: Structural diversity of mitochondria. Functional implications. Ann NY Acad Sci 1147: 171179 (2008).

Mannella CA, Marko M, Penczek P, Barnard D, Frank J: The internal compartmentation of rat-liver mitochondria: tomographic study using the high voltage transmission electron microscope. Microsc Res Tech 27: 278-283 (1994)

Mori H: Ultrastucture and stereological analysis of Leydig cells. In: Ultrastructure of endocrine cells and tissues. (Motta PM ed) Martinus Nijhoff Publishers, The Hague, 1984(p. 225-237).

Nathaniel DR: Helical inclusions and atypical cristae in the mitochondria of the rabbit thyroid gland. $J$ Ultrastruct Res 57: 194-203 (1976).

Perkins GA, Renken C, Martone ME, Young SJ, Ellisman M: Electron tomography of neuronal mitochondria: Three-dimensional structure and organization of cristae and membrane contacts. J Struct Biol 119: 260-272 (1997).

Prince FP: Mitochondrial cristae diversity in human Leydig cells: a revised look at the cristae morphology in these steroid-producing cells. Anat Rec 254: 534-541 (1999).

Prince FP: Lamellar and tubular associations of the mitochondrial cristae: unique forms of the cristae present in steroid-producing cells. Mitochondrion 1: 381-389 (2002).

Prince FP, Buttle KF: Mitochondrial structure in steroidproducing cells: three-dimensional reconstruction of human Leydig cell mitochondria by electron microscopic tomography. Anat Rec Part A 278: 454461 (2004).

Riede UN, Nobmann E: Atypische Lebermitochondrien adaptive Sonderformen? III. Parakristalline Einschlüsse im intracristalen Raum. Beitr Pathol 153: 319-329 (1974).

Riva A, Faa G, Loffredo F, Piludu M, Testa Riva F: An improved $\mathrm{OsO}_{4}$ maceration method for the visualization of internal structures and surfaces in human bioptic specimens by high resolution scanning electron microscopy. Scanning Microscopy 13: 111-122 (1999).

Riva A, Loffredo F, Uccheddu A, Testa Riva F, Tandler B: Mitochondria of human adrenal cortex have tubular cristae with bulbous tips. J Clin Endocrinol Metab 88: 1803-1806 (2003).

Riva A, Loy F, Isola R, Isola M,x Conti G, Perra A, Solinas P, Testa Riva F: New findings on 3-D microanatomy of cellular structures in human tissues and organs. An HRSEM study. Eur J Histochem 51 S. 1: 53-58 (2007).

Tandler B: Ultrastructure of the retrolingual salivary gland in the European hedgehog. J Submicrosc Cytol 18: 249-260 (1986).

Tandler B, Erlandson RA: Giant mitochondria in a pleomorphic adenoma of the submandibular gland. Ultrastruct Pathol 4: 85-96 (1983).

Tandler B, Phillips CJ, Nagato T: Parotid salivary gland ultrastructure in an omnivorous neotropical bat: Evolutionary diversity at the cellular level. Zool Scripta 17: 419-427 (1988). 
Tani E, Ametani T, Higashi N, Fujihara E: Atypical cristae in mitochondria of human glioblastoma multiforme cells. J Ultrastruct Res 36: 211-221 (1971).

Toyoshima K, Tandler B: Ultrastructure of the submandibular gland of the rabbit. Am J Anat 176: 469481 (1986).

Valdivia E, Berger JE: Atypical electron microscope structures in liver mitochondria. Pathol Microbiol 39: 112-114 (1976).
Walter RJ, Tandler B, Hoppel CL: Ultrastructural and biochemical effects of D-penicillamine on mouse hepatocytes. Anat Rec 197: 289-295 (1980).

Zirkin BR, Ewing LL, Kromann N, Cochran RC: Testosterone secretion by rat, rabbit, guinea pig, dog, and hamster testes perfused in vitro: correlation with Leydig cell ultrastructure. Endocrinology 107: 18671874 (1980). 